\title{
REFLEXIVIDAD EN LA OBRA DE EDUARDO HOLMBERG: EL ROL DE LA CIENCIA FICCIÓN Y LA FANTASÍA EN LA MODERNIZACIÓN Y EL CONTROL DE LAS MASAS
}

\author{
POR \\ JoAnna PAge \\ University of Cambridge
}

Eduardo Ladislao Holmberg (1852-1937) ha sido universalmente reconocido como modelo del pensamiento progresista en el siglo XIX tardío en Argentina. Fue pionero de la historia natural, dinámico director del nuevo Jardín Zoológico en Buenos Aires, fundador de la primera revista en el país exclusivamente dedicada a la biología, y el científico que mayor papel jugó en la difusión de las ideas darwinistas en Argentina, así como apasionado defensor, inspirado por Sarmiento, de la educación universal. Además de científico, Holmberg era un hombre letrado: a sus tratados científicos e informes de expediciones se suman varias novelas y hasta poemas. Aunque era partidario del positivismo tan fuertemente acogido por su generación, su ficción forja un rol extraordinario para la literatura y la fantasía utópica. Es aquí que el fervor modernizador de su trabajo como científico y educador se vuelve vulnerable a la duda y la ironía, y la reflexión que hacen sus novelas sobre su propio modo de enunciación nos ofrece una nueva perspectiva sobre los complejos discursos de la ciencia y el progreso en la Argentina de aquella época.

El excéntrico Viaje maravilloso del señor Nic-Nac al planeta Marte (1875) ha sido generalmente calificado como el primer texto de ciencia ficción en Argentina, y quizá en América Latina. Su extravagancia sorprende, sobre todo por ser el autor uno de los más destacados apologistas de las ciencias exactas. El mismo Holmberg explicó esta desviación hacia la fantasía al afirmar que este género, capaz de despertar la imaginación, podía por esa razón servir para la educación de las masas. En su mayor parte, los estudios publicados sobre la ficción de Holmberg se han limitado a la repetición de sus afirmaciones sobre el rol de la literatura fantástica en la divulgación de ideas científicas. Sin embargo, una investigación más detenida de Viaje maravilloso, tanto como la novela más plenamente utópica de Holmberg, Olimpio Pitango de Monalia (1915), deja en claro que el rol de la fantasía y la ciencia ficción en estos textos está impregnado de ambivalencia. El cuestionamiento reflexivo de su propio modo de textualidad arroja luz sobre el desarrollo del género de ciencia ficción en el contexto 
de una sociedad de modernización rápida, así como la circulación de la ciencia y la literatura en el imaginario cultural, y la manera en que ambos se juntaron para formar un nuevo público de lectores.

Las ficciones estrafalarias de Holmberg combinan el estilo gótico, la novela de misterio y las ciencias ocultas con usos poco ortodoxos de la historia natural, la antropología y la frenología. Eran tan desconcertantes para sus primeros lectores que durante muchos años no encontraron lugar en el canon literario. Viaje maravilloso se publicó como folletín en El Nacional en 1875 y después salió en formato libro el mismo año, pero no se reeditó hasta 2006, mientras que Olimpio Pitango de Monalia fue escrito en 1915 pero no se publicó hasta 80 años más tarde. El interés académico en Holmberg como escritor de ficción ha sido un fenómeno reciente. Se han publicado algunos estudios excelentes de su trabajo, entre ellos los que se encuentran en Relatos de época: una cartografía de América Latina, 1880-1920, de Adriana Rodríguez Pérsico (2010), Pioneros culturales de la Argentina: Biografias de una época, 1860-1910, de Paula Bruno (2011), y Espectros de la ciencia: Fantasías cientificas de la Argentina del siglo XIX, de Sandra Gasparini (2012). Estos estudios nos ofrecen la oportunidad de conocer mejor una época en ebullición y de intercambio febril entre la ciencia tanto las ciencias exactas como las ocultas- y la especulación, la prensa literaria y la política modernizadora del día en el contexto de grandes cambios sociales y culturales impulsados por la inmigración.

Quisiera extender estos trabajos al profundizar en el análisis de la exploración reflexiva del género fantástico en los textos de Holmberg. Como se ha demostrado, los cruces entre ciencia, fantasía y utopía en estos textos ponen de manifiesto la relación fluida entre la ciencia y formas esotéricas del conocimiento a fines del siglo XIX. Al mismo tiempo, indican cuáles eran los obstáculos, según la Generación del 1880, para la modernización en Argentina; nos permiten entender, también, la presentación equívoca de Holmberg del rol de la fantasía y la utopía literaria en ese mismo proceso de modernización. Holmberg cuestiona su propio empleo de la fantasía, y más ampliamente el papel que podría jugar la ficción y los usos literarios del lenguaje en el proyecto nacional de educación y modernización. Viaje maravilloso reflexiona de manera crítica sobre su propio uso de los géneros populares y la prensa popular para difundir ideas científicas, mientras que Olimpio Pitango de Monalia revela todavía con más claridad la ambivalencia de Holmberg hacia las fuerzas de la ficción y el misterio, herramientas en la educación de las masas así como en su manipulación. Este enfoque sobre la reflexividad de los textos nos llevará a una nueva percepción de un tema recurrente en el trabajo de Holmberg y de la política de su generación: la educación y el control de las masas, cuya afluencia desmesurada a finales del siglo XIX y comienzos del XX representaba un desafío enorme para cualquier concepción de la identidad nacional y produjo una transformación radical de la sociedad argentina. 


\section{CIENCIA Y FANTASÍA: CUESTIONES DE GÉNERO}

Si para algunos críticos, Viaje maravilloso puede identificarse como la primera novela de ciencia ficción en Argentina, otros describen el texto con más cautela como un ejemplo de proto-ciencia ficción. Nic-Nac no llega a Marte con la asistencia de un vehículo de alta tecnología, como una nave espacial, o por fuerzas explicadas desde la física, sino bajo la influencia de un médium, Seele. Se hace posible a través de una transformación en un "espíritu-imagen", una especie de materia espiritual que cruza las fronteras de espacio y tiempo pero sin embargo preserva la identidad del individual y sus percepciones sensoriales. Cuestiones de la ciencia y la tecnología se abordan en la novela junto con temas de naturaleza espiritual o esotérica, con toda naturalidad: “¿Qué es la vida? no sé; ¿qué es la muerte? no sé; ¿qué es el éter? ¿Qué es la electricidad? no sé, no $s e ́$ " (76). El espiritista y "sabio", Seele, tiene altos conocimientos de las ciencias físicas y morales, y su trabajo como médium se hace posible porque "[...] le era igualmente familiar la interpretación de un fenómeno cósmico, como la explicación de un fenómeno psíquico" (38). El punto de conexión más importante entre la novela y la especulación científica de su época se encuentra en su presentación de la teoría de la pluralidad de los mundos habitados, que fue motivo de exploración en la obra (literaria y no-literaria) del autor y astrónomo francés Camille Flammarion (1842-1925), textos que circulaban ampliamente en el momento en que Holmberg se puso a escribir el Viaje maravilloso. ${ }^{1}$ Sin embargo, como observa Gasparini, la novela difiere de la ciencia ficción temprana de Europa, como la de Jules Verne (1828-1905), porque no contiene ningún novum, y muestra menos interés en las posibilidades que ofrece el futuro desarrollo científico y tecnológico y más deseo por someter a una crítica social las condiciones actuales de su propia producción (Gasparini, "La fantasía científica” 127).

A primera vista, las visiones delirantes de Viaje maravilloso parecen totalmente fuera de lugar en la obra de un coleccionista meticuloso de muestras botánicas. Como científico, lo que quizás se habría esperado de Holmberg es que escribiera una novela naturalista, como las que escribieron muchos de los médicos con afán literario en esa época (Laera, "Introducción" 9). De hecho, muy lejos de mostrar un claro intento pedagógico, Viaje maravilloso se vale de un humor travieso para romper con toda seriedad. La ausencia relativa de la ciencia "dura" en la novela se ha explicado de distintas maneras. Se suele observar, por ejemplo, que en esa época la ciencia todavía no se había separado del espiritismo. La elección de Holmberg de un modo no-tecnológico para el viaje interplanetario de Nic-Nac rinde homenaje a la gran influencia de las creencias

1 De los textos de Flammarion, tres de los que fueron traducidos al español tuvieron una influencia particular en el pensamiento y la obra de Holmberg: La pluralidad de los mundos habitados (1873), Los mundos imaginarios y los mundos reales (1873) y Lumen (1874). La fecha provista en cada caso es la de la primera versión publicada en español. 
espiritistas en el Buenos Aires del siglo XIX tardío, donde las escrituras de Allan Kardec (1804-1869) tenían una circulación importante. También demuestra, sin duda, la influencia de Flammarion, cuya obra Lumen (1872) presenta el espíritu incorpóreo como modo de transporte cósmico (Haywood Ferreira 38). Por otro lado se ha sugerido que, si los viajes de Verne se hicieron en vehículos ya disponibles en las ciudades industrializadas de Europa, la elección de Holmberg de un vehículo no-tecnológico -la transmigraciónrefleja la ausencia relativa de la tecnología no sólo en la vida actual sino también en los discursos públicos de Argentina en esa época. Como sostiene Carlos Pérez Rasetti, los discursos de la Generación del 1880 no fueron construidos por ingenieros sino por abogados y médicos, y la preocupación principal de sus programas políticos y económicos no fue desarrollar la tecnología industrial sino formar una fuerza laboral de inmigrantes unida y ordenada que propulsaría el progreso de la nación al explotar sus abundantes recursos naturales (Pérez Rassetti 213).

En muchos sentidos, sin embargo, la novela de Holmberg no está tan ajena a otras de su generación, comprometidas como estaban con el Realismo, el Naturalismo y el Costumbrismo. Como observa Pablo Crash Solomonoff, “[...] mientras Martín Fierro cruzaba los límites de la frontera de indios, Nic-Nac cruzaba los de la atmósfera” (13): tanto el poema épico de José Hernández como la novela fantástica de Holmberg se nutren del mismo espíritu de exploración con el fin de la integración y modernización de la nación, y al fin y al cabo, en la mentalidad del siglo XIX, los indios bien podrían haber sido extraterrestres. Holmberg dirige una mirada costumbrista hacia la fauna y flora de Marte, y analiza la vida diaria de sus habitantes con una atención antropológica. Sus descripciones detalladas de la geografía marciana, que incluyen su distancia en leguas del sol a diferentes puntos de su camino elíptico por la galaxia, representan intervenciones de una exactitud incongruente en este viaje fantástico del espíritu. Una sensibilidad romántica hacia el poder de la imaginación y la vida espiritual se combina con una precisión en trazar formas geológicas que parece tomada de una de las crónicas expedicionarias del mismo autor. Si la novela nos presenta con varios ejemplos del esoterismo, como la escritura automática, también vemos el fervor clasificador del historiador natural de siglo XIX que observa que, en Marte, "Cada ave tiene su nido, cada flor su perfume, cada insecto su matiz, cada pueblo sus costumbres, cada secta sus preocupaciones" (Holmberg 133).

¿Hasta qué punto se sintetizan la fantasía y la ciencia en Viaje maravilloso para formar una visión unida y coherente? Para Antonio Pagés Larraya, se mantienen en una tensión irreducible. Nos alerta contra la tentación de buscar correlaciones entre el naturalista y el escritor de cuentos fantásticos: cuando inventaba sus ficciones, Holmberg sencillamente dejó a un lado el pensamiento metódico, la paciencia y el orden que requiere la investigación de laboratorio. Afirma que "el hombre de ciencia y el escritor se regían por imperativos diferentes” (Pagés Larraya 93) y que los mundos fantásticos 
representaban una especie de válvula de escape que pudiera aliviar las presiones del trabajo intelectual. Concede, sin embargo, que tanto la investigación de Holmberg sobre los misterios de la naturaleza como su creación de mundos imaginarios forman parte de una búsqueda más amplia de "la belleza y el bien" (Pagés Larraya 96). Bonnie Frederick relega la ficción a un rol parecido, de compensación, con relación a la ciencia cuando sostiene que Holmberg y otros intelectuales de la época, como Carlos Bunge y Eduardo Wilde, "[...] construyen un discurso científico de poder y autoridad. Pero se vuelcan hacia el discurso literario por el lenguaje de fracaso y angustia: el fracaso de no lograr su meta de una ciencia objetiva, el fracaso de no conocer el mundo lo suficiente para usar sus conocimientos para el bien, y la angustia frente al sufrimiento humano que su ciencia no puede curar" (Frederick 59; traducción mía).

Para otros críticos, la ficción juega un rol más activo en los textos híbridos de Holmberg en relación con la divulgación de la ciencia: no como compensación ni como alivio frente a sus exigencias, sino como un medio clave para la diseminación de nuevos conceptos y teorías. En un momento en que muchas disciplinas todavía se hallaban en vías de formación, la ficción de Holmberg provee un espacio crucial para la exploración de ideas esotéricas, disidentes, excéntricas o improbables que (todavía) no habían sido aceptadas por las corrientes principales de la ciencia. Como mantiene Gasparini, "Estas ficciones experimentan, efectivamente, con esas hipótesis descartadas, consideradas erróneas o imposibles por el ámbito académico" (Gasparini, Espectros de la ciencia 22). Es de este modo, sugiere Gasparini (tal como lo hace Frederick), que escritores como Holmberg encontraron en la literatura un espacio apropiado para un cuestionamiento subrepticio del rol de la ciencia en la sociedad moderna, pero también para una discusión sobre otras formas de conocimiento que aspiraban entrar al círculo de aprobación académica (Gasparini, Espectros de la ciencia 22-23). Las disciplinas y doctrinas nuevas y antiguas, aceptadas y contestadas -la fisionomía, la astronomía, la sociología, la geología, la biología, la psicología, el espiritismo, el materialismo-luchan para ganar prominencia en una novela como Viaje maravilloso. La ficción aporta un escenario para conflictos sin resolver entre las distintas ramas de conocimiento que caracterizaban los fines del siglo XIX y comienzos del XX. La literatura de esta época, como afirma Alejandra Laera, muestra el ascenso de ciertas formas de conocimiento por encima de otras, y la creciente institucionalización de aquellas (en museos, institutos y bibliotecas), pero a la misma vez resucita estos debates en sus propias páginas o desafía esta regulación al proponer formas alternativas de conocimiento u otras maneras de clasificarlas (Laera, "Introducción" 9).

Para la mayoría de los que han estudiado la obra literaria de Holmberg, sin embargo, la síntesis de fantasía y ciencia no reúne regímenes opuestos sino discursos finalmente compatibles. Estos críticos hacen eco - a veces sin escudriñarlas demasiado-de las ideas expresadas por Holmberg sobre el rol de la literatura fantástica en la divulgación de 
descubrimientos científicos. Pablo Crash Solomonoff, por ejemplo, halla una continuidad armoniosa entre las actividades científicas y novelísticas de Holmberg, las dos siendo en lo esencial formas de educación: "[...] su proyecto pedagógico, así como literario, consistió en enseñar divirtiendo y en divertir(se) enseñando el amor al conocimiento" (Crash Solomonoff 23). Rachel Haywood Ferreira observa que Holmberg percibía la literatura y la ciencia como "compañeros naturales" en el desarrollo de una nación moderna (Haywood Ferreira 36). Concluye que la elección de Holmberg de la fantasía y la ciencia ficción como modo de dirigirse al público se justifica porque $-\mathrm{y}$ aquí se apropia de las palabras del editor imaginario de la novela- "todos aquellos elementos que constituyen el conjunto, no habrían podido expresarse, tal vez, de otra manera" (Holmberg en Haywood Ferreira 42).

No obstante, hay otra perspectiva que nos podría ayudar a entender la mezcla de fantasía y ciencia y la obra de Holmberg. El análisis de la novela que sigue pondrá énfasis sobre su indagación reflexiva del poder de la ficción y la fantasía, y precisamente cómo se imagina el rol de éstas en extender el conocimiento científico a las masas. Veremos que se trata de un poder plenamente abierto al abuso, y ahí radica la duda de Holmberg sobre su propio empleo de la ficción y la fantasía en la misión de modernizar y educar a la sociedad.

\section{UTOPÍA, SÁTIRA Y LA MODERNIZACIÓN}

Los defectos de la sociedad argentina que-según el autor-obstaculizaban el proceso de modernización se dramatizan en los viajes de Nic-Nac a tres ciudades en Marte: una ciudad utópica, otra distópica, y otra más que tiene un asombroso parecido con el Buenos Aires que conocía Holmberg. La útopica Sophopolis es un lugar de luz y festividad, y sus habitantes son generosos, igualitarios y modelos de belleza e inteligencia. Sin embargo, está trágicamente amarrada a su ciudad hermana, Theopolis: un lugar lúgubre y silencioso, y lleno de miserables hipócritas religiosos.

En Sophopolis, todos los ciudadanos son estudiantes, sin tener en cuenta la edad o sexo, e intelectuales de muchas otras naciones se reúnen en la ciudad para trabajar juntos con el fin de destapar los secretos de la naturaleza. Sophopolis está gobernada por hombres de ciencia y sabiduría, cuyo liderazgo no está contaminado por mercantilismo, ni dogmatismo religioso ni faccionalismo político. En el centro de la ciudad se eleva la Academia. Es un lugar de luz brillante, alumbrado por "el magnífico resplandor de su ciencia" (Holmberg, Viaje maravilloso 110). Además de ser la sede de debate erudito sobre asuntos científicos es, a la misma vez, el consejo superior al gobierno y su principal cuerpo legislativo. Es tal su centralidad a la sociedad cívica que hasta las ceremonias de casamiento se celebran allí. La afiliación a la Academia está abierta a todo ciudadano que desee trabajar para la felicidad y el bienestar de todos. Si se trata de un centro de 
enseñanza y debate, allí también congregan la sociabilidad y la risa: es, "en una palabra, donde se aprende a vivir" (Holmberg, Viaje maravilloso 107). Esto no significa que la Academia esté siempre regida por la armonía perfecta: la disensión y la rivalidad no le son ajenas, porque son condiciones necesarias para el debate riguroso. Sin embargo, mociones inteligentes y justas siempre son aprobadas por unanimidad. Aunque existen instituciones parecidas en Theopolis, nos cuenta el narrador, no funcionan bien, dada la preferencia de los theopolitas por el aislamiento.

Cuando Nic-Nac y Seele llegan a la capital de la Nación de Aureliana (Argentina por otro nombre), Holmberg cambia el modo utópico por el satírico. En lugar del autogobierno por consenso y debate racional, aquí Nic-Nac encuentra “[...] un pueblo siempre agitado y turbulento, a la vez que generoso [...]" (144). Esta ciudad beligerante le debe sus divisiones a la mezcla heterogénea de nacionalidades y culturas entre sus inmigrantes. De este caos surge una lucha interna que muchas veces conduce a la erupción de violencia y a esas escenas de protesta social que son "[...] tan comunes en los pueblos que no han cimentado aún su organización interna[...]” (Holmberg, Viaje maravilloso 147). Un sentimiento nacional en rápido declive es incapaz de controlar sus "pasiones mezquinas". Estamos muy lejos del reino de la razón que impera en Sophopolis: aquí, las voces más altas son las menos informadas y más tercas. Esta generación, tan diferente -como nos recuerda Holmberg- de la que vivió la historia gloriosa de Argentina, sólo sabe buscar la inspiración y la revitalización en un estado de agitación constante, en guerras civiles o conflictos internacionales.

Holmberg insiste repetidamente en que los extranjeros forman la mayoría de los habitantes de la ciudad, y observa que "En los semblantes de la aglomerada población no se podrían señalar los rasgos del tipo nacional, absorbido, devorado por el torbellino de un cosmopolitismo inexplicable" (Holmberg, Viaje maravilloso 153-54). Es esta heterogeneidad que efectivamente se borra en la utópica Sophopolis. Si la mezcla lingüística se volvía un factor de creciente importancia en la fragmentación cívica en Buenos Aires de la época, es significativo que en Sophopolis, Nic-Nac encuentre con placer que puede entender perfectamente a los marcianos sin necesidad de traducción. Toda diferencia cultural está eliminada en la representación utópica de Sophopolis, y brillan por su ausencia las masas que ya empezaban a engrosar la población de Buenos Aires en la década del 1870. La cultura académica de Sophopolis y la armonía de sus ciudadanos están amenazadas por intrusos que llegan desde afuera, que buscan la disensión y no comparten su respeto por la vida. Finalmente, la tolerancia con la que los sophopolitas tratan a estos intrusos conduce a su perdición, y una guerra provocada por Theopolis deja en ruinas a las dos ciudades. ¿Deberíamos leer aquí un comentario alegórico sobre la actual condición de Buenos Aires, y un rechazo a las masas inmigrantes? Holmberg no emplea las misma invectiva contra los recién llegados de los que Alberdi (1810-1884), se queja en un apéndice a sus Bases de 1873 -sólo dos años antes de 
la publicación de Viaje maravilloso- donde su célebre máxima "gobernar es poblar" sólo tendría efecto si los inmigrantes fueran educados y civilizados, y que, de no ser así, "[...] poblar es apestar, corromper, degenerar, envenenar un país cuando en vez de poblarlo con la flor de la población trabajadora de la Europa, se le puebla con la basura de la Europa atrasada o menos culta" (Terán 48). Es evidente también que Holmberg no presenta ni un argumento por la pureza racial ni un lamento por su pérdida. Adhiere a un entendimiento bien decimonónico de la jerarquía racial, al observar que generaciones sucesivas de theopolitas se perfeccionan, paso a paso, por la mezcla de genes que resulta del rapto de mujeres sophopolitas. Sin embargo, como mantiene Bruno, las referencias que hace la novela a la mezcla racial " "...] no están encorsetadas de manera rígida por matrices comteanas, darwinianas, spencerianas o lebonianas" (Bruno 182).

De hecho, Holmberg no se interesa principalmente por la mezcla racial y sus posibles consecuencias sino por la falta de unidad en el corazón de la nación argentina, que no tiene idioma, raza, cultura ni historia compartida a base de la cual se podría construir una sensibilidad nacional. Las perspectivas de Holmberg con relación a la cuestión de la unidad nacional se hacen más claras si examinamos su intervención en el debate contemporáneo sobre la libertad de la prensa, el cual está insertado en la novela como si se tratara de un debate de la Academia en Sophopolis. Holmberg expone en la novela la misma posición que adoptó en la encendida polémica que se desarrollaba en los años alrededor de la publicación de Viaje maravilloso. Defendió el derecho de la prensa a poner en duda las políticas del gobierno y de pedirle cuentas, como única manera de evitar abusos autoritarios, pero sostuvo que no debería permitírsele desacreditar o difamar a la nación. Las diferencias son aceptables, y hasta necesarias para un debate productivo y un gobierno justo, pero no lo es un espíritu divisor que intente desmontar la nación.

Holmberg encuentra difícil imaginar que el espíritu fraternal que rige en Sophopolis pudiera replicarse en Buenos Aires, si se toma en cuenta las divisiones enormes de clase, cultura y hasta idioma. Como mantiene en Viaje maravilloso,

[... la amistad en su valor absoluto no puede existir, o al menos no puede ser duradera entre dos individuos cuyas fuerzas no están equilibradas: el rey jamás será amigo del artesano, ni el noble del plebeyo, ni el rico del pobre, ni el fuerte del débil, ni la mariposa de la golondrina, ni la paloma del milano, ni la liebre del galgo, ni el gato del perro, ni Nic-Nac de Seele... (Holmberg, Viaje maravilloso 170)

Hay un orden y una jerarquía natural que no pueden esquivarse. Si en su descripción de Sophopolis Holmberg expresa una confianza suprema (y sarmientina) en el poder civilizador y unificador de la educación, aquí su convicción vacila: las diferencias y desigualdades de Buenos Aires son tantas que parece imposible que se superen. En el concepto nacionalista de Holmberg -igual como en el de Sarmiento y Alberdi-dominan los valores compartidos de la democracia, la libertad y la educación por sobre cualquier 
noción de territorio. Es por eso que no sólo el orden social sino también el mismo concepto de la nación se ven seriamente amenazados, según la visión de Holmberg, por el influjo masivo de inmigrantes de bajo nivel educativo y los problemas concomitantes de desigualdad y diferencia social, lingüística y cultural. La nación no puede funcionar como debe funcionar, como un espacio de debate razonado, de intercambio de ideas entre iguales, y de educación universal.

FICCIÓN, FANTASÍA Y LA EDUCACIÓN DE LAS MASAS: LA REFLEXIVIDAD EN LA OBRA DE HOLMBERG

En otros proyectos, el compromiso de Holmberg con la divulgación pública de ideas científicas le llevó a fundar en 1878, con Enrique Lynch Arribálzaga (1856-1935), El naturalista argentino: Revista de historia natural. Como explica Bruno, la revista se apartó de la norma de la época para las publicaciones científicas, tanto en su estilo como en su enfoque. Sustituyó las listas de publicaciones recibidas y los trabajos científicos detallados, muchas veces escritos en lenguas extranjeras, por artículos sobre una gama más amplia de temas, “escritos en un registro ameno y didáctico que, en algunos casos, rozaba el relato de aventuras". La revista respondió a algunas de las preocupaciones de una nueva generación de científicos naturales en Argentina que no estaban conformes con la manera en que se desarrollaba la disciplina, e hizo claro su intento a generar un espacio para la diseminación de ideas científicas más allá del mundo cerrado de los especialistas académicos (Bruno 155).

En muchos sentidos, la ficción de Holmberg puede leerse como parte de esta misión más extendida de difundir el conocimiento más allá de las esferas restringidas de las élites educados y crear un público de lectores más informados. En el segundo número de El naturalista argentino, Holmberg critica la falta de compromiso con el público por parte de muchos de sus colegas científicos, que en su mayoría habían llegado de Europa, y propone que "el pueblo, curioso por naturaleza, pero cuya curiosidad ha sido mal encaminada, necesita la forma animadísima de un Julio Verne, para poder escalar paso a paso las maravillas que la Naturaleza despliega en todas sus creaciones" (Holmberg, "El museo de Buenos Aires" 33-42).

Diana Cazaux sostiene que la divulgación de ideas científicas en Argentina en la época 1862-1942 corresponde fielmente a la tradición anglosajona identificada por Sergi Cortiñas; esta tradición, a diferencia de la italo-renacentista, la francesa y la pruso-alemana, está marcada por la multiplicación y la diversificación de vías y modos de divulgación, que incluyen ensayos, novelas, poesía, conferencias, literatura infantil, artículos de prensa y textos audiovisuales (Cazaux 83). ${ }^{2}$ La prensa periódica,

Véase también Cortiñas; Laera, "Novelas argentinas (circulación, debates y escritores en el último cuarto del siglo XIX)" 97. 
el espacio más prominente de la actividad literaria y crítica en Argentina del siglo XIX tardío, juntó muchos de estos distintos géneros. Como observa Laera, en este momento de expansión vertiginosa, el hecho de que este espacio estuviera compartido tanto por textos cultos como por los populares tenía el efecto de borrar diferencias entre estos dos tipos de producción (Laera, "Introducción” 105). Se creaba de esa manera un público diverso y amplio.

Con algunas excepciones, todas las obras ficcionales de Holmberg se publicaron primero como folletines. En Viaje maravilloso, sin embargo, el marco narrativo delata la ambivalencia de Holmberg hacia el uso de la prensa popular para la diseminación de ideas científicas. En el prólogo al cuento de Nic-Nac, el editor ficticio de Holmberg parodia la frivolidad y el sensacionalismo de la prensa, en que un hecho político de alta gravedad -el descubrimiento de un complot para incitar disturbios entre trabajadores $-^{3}$ queda olvidado en el apuro de publicar la historia del viaje de Nic-Nac a Marte. Ni siquiera hay tiempo para corregir los errores ridículos de la primera versión apresurada de la narrativa antes de que la historia completa se abandone y dos días después ya se olvida, "[...] lo que prueba una vez más cuán pasajeras son las grandezas humanas [...]" (Holmberg, Viaje maravilloso 31). Contra toda probabilidad, nos cuenta el narrador, una prensa de la ciudad decide publicar la historia de Nic-Nac. De esta manera, el texto que leemos se anuncia como un intento a contrarrestar los caprichos del periodismo y sus lectores. En un tono satírico y pragmático, el narrador reflexiona que "En nuestros tiempos, las ideas serias no cumplen su destino sino envueltas en el manto de la fantasía" (Holmberg, Viaje maravilloso 32). El escritor del folletín se salió con la suya: con un juego de manos ha logrado intercalar un texto de mayor importancia que podría quizá poner en duda las ideas superficiales de los lectores de la prensa amarilla. El narrador nos ruega continuar hasta llegar al informe de Nic-Nac, porque "quizá resuelva alguna cuestión importante" (Holmberg, Viaje maravilloso 32).

El recelo de Holmberg hacia su propio experimento genérico -el de usar el folletín para diseminar las ideas científicas- llega a aclararse en el epílogo, cuando el editor ficticio de la narrativa de Nic-Nac interviene para informar a los lectores sobre qué partes de la narrativa pueden considerarse educativas y cuáles son meros desvíos fantásticos. La esperanza del editor de que descubriéramos respuestas a preguntas importantes se ha convertido en el “¡Horrible desengaño!” (Holmberg, Viaje maravilloso 177). Lo que puede rescatarse de la historia de Nic-Nac, nos informa, es su fidelidad a la teoría de la pluralidad de mundos habitados, que no es ningún producto de una imaginación recalentada sino una teoría importante defendida por una de las mentes más brillantes de Europa, entre las cuales figura Flammarion. Es, nos dice, un homenaje necesario a la grandeza del universo, y un reconocimiento humilde de nuestra ignorancia de sus formas

Se refiere a la breve Guerra Civil de 1874 que siguió el resultado disputado de las elecciones presidenciales. 
y su evolución. Por lo demás, sin embargo, el editor ahora muestra escepticismo hacia la versión de hechos ofrecida por Nic-Nac, a quien le han diagnosticado una "manía planetaria" (Holmberg, Viaje maravilloso 179) antes de meterlo en un manicomio. La razón, concluye, no puede aceptar el cuento del viaje de Nic-Nac: fue sólo la fantasía de un loco, cuya imaginación febril se calmaría con la ayuda de una ducha fría.

A diferencia de la mayoría de los autores de ciencia ficción, Holmberg no trata de convencer a sus lectores de la plausibilidad de los nuevos mundos que crea, ni de la credibilidad de su base, sentada en una extrapolación de la ciencia del día. El editor siembra dudas importantes sobre la historia de Nic-Nac y hasta critica su estilo narrativo, quejándose de "esa vaguedad indefinible de los conceptos"(Holmberg, Viaje maravilloso 179). Es evidente su confusión: por un lado afirma que "no vacilamos en aceptar las opiniones del doctor Uriarte", y que por lo tanto los hechos narrados representan nada más que la fantasía de un demente, pero por otro lado siente dolor al pensar que "[...] un hombre que ha hecho lo que ningún otro hombre, se vea reducido a tan triste situación" (Holmberg, Viaje maravilloso 180). La historia de Nic-Nac se coloca bajo tachadura: tuvo lugar y, al mismo tiempo, no tuvo lugar.

De esta manera, el marco narrativo tiene la función de desacreditar al relato central de Viaje maravilloso. Se trata de un recurso muy inusual en la ciencia ficción. Permite a Holmberg señalar la reacción poco receptiva de las instituciones de la época hacia lo paranormal y posibles descubrimientos nuevos. Pero a la misma vez revela sus dudas acerca del medio popular de divulgación que ha elegido: ¿cómo han de identificar sus lectores lo que es fantasía y lo que es ciencia? ¿El cuento de Nic-Nac realmente pone el contrapunto a la frivolidad de la prensa amarilla que critica o simplemente cae en su sensacionalismo? ¿Puede usarse la prensa como herramienta de la educación si representa, como la prensa de Aureliana, "el eco nato de las opiniones del pueblo" (Holmberg, Viaje maravilloso 154) y se limita a perpetuar disputas ignorantes sin arrojar luz sobre la cuestión? De hecho, público y prensa en Viaje maravilloso parecen estar atrapados en un círculo de ignorancia: cuando Seele es acusado de charlatán, el narrador nos recuerda que el público siempre repite, sin mejor criterio, la calumnia de la prensa popular, y por lo tanto "[...] el pueblo no tiene, ni puede, ni debe tener opinión [...]" (Holmberg, Viaje maravilloso 40). Declaraciones de este tipo no llegan precisamente a la aprobación de la capacidad, ni de la prensa ni de sus lectores, para la fiel diseminación de ideas científicas.

En la relación entre ficción y ciencia en la novela de Holmberg podemos apreciar una divergencia importante con los textos de Jules Verne y H. G. Wells (1866-1946), sus contemporáneos europeos más conocidos. ${ }^{4}$ Arthur B. Evans contrasta el uso de la

4 Viaje maravilloso y Dos partidos en lucha antedatan la primera novela de Wells por veinte años, pero las obras más conocidos de Wells caen en el período que separa la ficción temprana de Holmberg de su última novela, Olimpio Pitango de Monalia (1915). 
ficción de parte de Verne para enseñar la ciencia con el uso de la ciencia para desarrollar la ficción que se encuentra en las novelas de Wells. La ciencia ficción de Verne "supone un rol predominantemente pedagógico" para el discurso científico, mientras que en Wells, su función está "[...] más ligada a la exposición: facilitar la progresión de la trama, ayudar en el desarrollo de efectos especiales y el distanciamiento del lector, y crear la verosimilitud [...], lo que permite a los lectores concentrarse plenamente en las ramificaciones humanas de la historia [...]" (Evans 17, 21; traducción mía). Al fin y al cabo, Viaje maravilloso muestra poco del espíritu directamente pedagógico que impregna los viajes ficticios de Verne. Tampoco hace uso de la ciencia para prestar ni plausibilidad ni una dimensión más humana a la narrativa. La novela forja, en cambio, un tercer camino, el de la reflexividad, que investiga la naturaleza misma de la relación entre fantasía y la divulgación de la ciencia.

En varias ocasiones, el uso de la fantasía que hace Holmberg claramente no encaja con su deseo expresado de educar a través de una estimulación de la imaginación. Envolver la ciencia en la fantasía puede provocar una sensación de asombro y misterio en el lector, pero al mismo tiempo lo distancia del verdadero conocimiento científico. A veces, podría decirse que Holmberg muestra menor interés en abrir las puertas del laboratorio al hombre de la calle y más interés en preservar el rol pedagógico y el estatus elevado de la élite intelectual. En Viaje maravilloso, las ceremonias religiosas de Theopolis se denuncian como un intento eficaz de retener a la población en la esclavitud: si nadie entiende la música sacra de los coros es porque de no ser así, "perderían su carácter eminentemente místico" (Holmberg, Viaje maravilloso 69). Sin embargo, Holmberg hace repetido uso de las mismas técnicas de obnubilación cuando envuelve la ciencia en fantasía. Como el viaje de Nic-Nac no es reproducible con la ayuda de ningún medio técnico, sus descubrimientos quedan en el dominio de lo esotérico. Cuando nos asegura el narrador, muy al estilo romántico, que "El sueño es el eslabón que liga el espíritu humano con los grandes misterios de la Naturaleza" (Holmberg, Viaje maravilloso 38), no le proporciona al lector común que quiera acceder a esos misterios las herramientas que necesita para hacerlo, ni le anima a conocerlos a través de la observación metódica científica. El uso de la fantasía para ofuscar los procesos racionales de la investigación científica es aún más evidente en otra novela de Holmberg, Dos partidos en lucha, que enfoca más claramente la ciencia "dura". Como mantiene Gasparini, el episodio en que se produce la resucitación del espécimen reseco de mimosa "[...] combina los pasos del método experimental con la iluminación de la magia, de lo revelado a unos pocos" (Gasparini, Espectros de la ciencia 96).

Cuando los diarios argentinos más importantes del día se hacían cargo de explicar los últimos descubrimientos científicos a sus lectores, Diana Cazaux sugiere que, de hecho, el proceso de "traducir" la ciencia terminaba con reforzar la distancia entre los científicos y el público. La ciencia tenía lugar en laboratorios mágicos, a los cuales 
eran invitados los periodistas por el científico-mago para presenciar su último invento (Cazaux, 95-96). Como observa Cazaux, "Eso no hizo más que agregarle una capa de magia y distancia a todo el asunto científico: en la medida en que el lector sentía que para llegar a la ciencia necesitaba un intermediario (y uno de peso, como un diario), la ciencia se hacía inaccesible, remota, imposible de transformar en propia” (96).

Este proceso obnubilante se ve también en el abandono por parte de la prensa de un lenguaje neutro, claro y conciso para la descripción de avances tecnológicos a favor de palabras como "sorprendente" o "asombroso" (Holmberg, Viaje maravilloso 94-95). Esta técnica podría haber inspirado fascinación por parte de los lectores, pero al mismo tiempo los distanciaba: se necesitaba un mago (o en el caso de Viaje maravilloso, un médium) para hacer funcionar la ilusión y explicarla. Los científicos se volvían los sacerdotes de una nueva religión, dejando embelesadas a las masas pero negándoles acceso al sanctasanctórum.

Inmediatamente después de la resurrección cuasi-mágica de la "sensitiva" en Dos partidos en lucha, el científico Grifitz explica: "Sirvo una doctrina científica: el darwinismo. Tarde o temprano llegará a ser una doctrina política y necesito cierto misterio en mi conducta" (89). Cuando la ciencia juega un papel en el poder político, como sugiere esta declaración enigmática, una dosis de obnubilación es altamente eficaz. Es este recelo por parte de Holmberg hacia las operaciones mitificantes que refuerzan el poder político que pasa a primer plano en su última obra de ficción, Olimpio Pitango de Monalia. En su obra temprana, como hemos visto, expresa dudas con respecto al uso del género fantástico en la educación científica de sus lectores, pero allí sólo vislumbramos algo de lo que deviene, más tarde, en una visión más completa de cómo la fantasía puede emplearse para diseminar la ciencia pero, a la misma vez, para apoyar el poder político de la élite.

\section{DE LA FICCIÓN A LA DEMAGOGIA POLÍTICA Y VICEVERSA}

La ambivalencia de Holmberg hacia el uso de la ficción para la educación de las masas alcanza su cumbre cuando vuelve treinta años más tarde a escribir una novela, Olimpio Pitango de Monalia. Monalia es un paraíso terrenal cuyos ciudadanos inteligentes se autogobiernan a base del respeto universal para la justicia, lo cual ahorra la necesidad del conflicto político. Es una meritocracia en la que la aptitud es el único criterio en el reparto de las responsabilidades. La nación ha recibido el progreso con entusiasmo, y la ausencia de un sistema legal burocrático y enrevesado ha permitido a los ciudadanos dedicar su capacidad colectiva intelectual a fines más útiles. La utopía empieza a desmoronarse, sin embargo, cuando el orador político Olimpio Pitango los convence que no pueden declararse una nación moderna porque les faltan partidos políticos, instituciones y todo el boato del nacionalismo decimonónico latinoamericano: 
himnos nacionales, próceres, comités, constituciones, desfiles y feriados oficiales. Quiso la suerte que Monalia se encontrara cerca de la costa sudamericana, así que no faltaban repúblicas cercanas que pudieran proporcionar ejemplos excelentes de estas cosas, y Olimpio Pitango viaja hasta Buenos Aires para aprender todo lo que hay para saber.

Con el nacimiento de los partidos políticos, Monalia pierde todos los beneficios que caracterizaban su existencia anterior: paz, unidad, bienestar y buenas relaciones con otras naciones. Se disipa la inteligencia paciente con la cual sus ciudadanos habían escuchado a pedagogos extranjeros con menores capacidades, y los habitantes se convierten en las masas irreflexivas y fácilmente engañadas que poblaban las páginas de estudios muy conocidos de la época, como los de Gustave Le Bon (1841-1931) en Francia y José María Ramos Mejía (1849-1914) en Argentina. Proclamada con suficiente elocuencia y brío, cualquier tontería que les digan los nuevos maestros de la retórica política basta para electrizar a las multitudes de Monalia. Definitivamente llegan a ser las masas de Le Bon (que influyeron tanto en las de Ramos Mejía), para quienes "No son, pues, los hechos mismos, en sí, los que afectan a la imaginación popular, sino más bien el modo como se presentan" (Le Bon 57). Las masas responden a imágenes fuertes que conmueven el espíritu en vez de estimular la mente, sugiere Le Bon, hasta el punto de que "Conocer el arte de impresionar la imaginación de las masas equivale a conocer el arte de gobernarlas" (57). Olimpio se lanza a inventar un pasado ficticio de ruinas venerables para Monalia y logra convencer a los ciudadanos de la verdad de sus fantasías desabridas, y consecuentemente despierta en ellos un nacionalismo vulgar e irracional.

Sin embargo, mientras que Holmberg desconfía de la vulnerabilidad de la imaginación frente a las artimañas de la demagogia política, insiste en que siga siendo el elemento más crucial en el desarrollo de la inteligencia humana. Si Monalia era una utopía, Holmberg nos informa al final de la novela que no lo había sido por completo, porque algo se había descuidado: el arte del cuento. Cuando llegan noticias al gobierno del poder cautivador de una narradora, Olimpio Pitango está impaciente por saber su secreto. Como ella le recuerda, " [...] la facultad más necesaria para el hombre intelectual es la imaginación [...]" (Holmberg, Olimpio Pitango 181). Sin imaginación, mantiene ella, ni matemáticos ni químicos ni físicos podrían descubrir las maravillas del universo o resolver los problemas de sus disciplinas; ni músicos ni poetas ni pintores podrían emprender sus vuelos creativos. Hasta la historia y la filosofía encuentran en la imaginación justo lo que les falta en los mejores archivos y talleres. La imaginación es el fundamento, no sólo de la creatividad artística, sino de todo descubrimiento científico e intelectual.

Frente al apabullante positivismo de su época, Holmberg afirma repetidamente en su ficción que la Razón no puede contra la fuerza de la imaginación. Como explica con elocuencia Olimpio Pitango:

[...] hay algo, Señora, Señores, que la Razón más poderosa no puede jamás destruir. Se derrumban las monarquías porque las repúblicas son la encarnación del más alto 
progreso político; se extinguen los pueblos porque la lucha por la vida los desaloja; se debilitan y mueren las religiones porque la razón las excluye; pero el sentimiento humano es la flor inmarcesible de la civilización y del progreso, porque está servido por la imaginación y la fantasía que son las energías motrices de la ciencia y de los descubrimientos" (Holmberg, Olimpio Pitango 190)

De hecho, la llamada Razón falla rotundamente en Olimpio Pitango. En un intento excesivamente entusiasta por descubrir ruinas y reliquias para fundamentar la base de una narrativa histórica nacionalista - esencial, al parecer, para la construcción de una nación moderna- varios equipos de paleógrafos se precipitan al anunciar el descubrimiento de documentos antiguos que más tarde se revelan como falsificaciones. Como sugiere Adriana Rodríguez Pérsico en su análisis de la novela, la literatura y la imaginación están dotadas de mayor poder que la ciencia en la explicación de la realidad: "Si la ciencia se equivoca, la literatura retiene la capacidad de actuar sobre la realidad, transformándola y aún inventándola" (Rodríguez Pérsico, “Las reliquias del banquete”" 386).

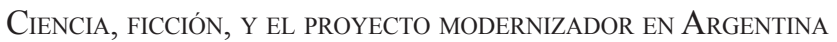

Si es cierto que recurrir a los géneros de fantasía y aventuras -igual que en las novelas de Verne- ayudó a popularizar la ciencia en el siglo XIX tardío, con su novela Holmberg también da una señal de advertencia: la fantasía puede liberar la imaginación de las masas e inspirar en ellas una pasión por el descubrimiento y el conocimiento, pero puede usarse, a la misma vez, para controlarlas y manipularlas. La fantasía se presta a la creación de espectáculos deslumbrantes y cegadores, obrando para confirmar el estatus de la élite política y científica al mismo tiempo que pretende democratizar la ciencia y difundir sus teorías y hallazgos entre las clases menos pudientes.

La ciencia en Argentina después del 1880 se centraba cada vez más en la regulación de las masas, con la llegada de nuevas tecnologías - como la identificación mediante huellas digitales- que tenían como fin el contener y el controlar de la población (Rodríguez, Civilizing Argentina 5). En Viaje maravilloso de Holmberg vislumbramos una visión alternativa de la ciencia como descubrimiento y fomento de la imaginación, al alcance de todos, pero está claro que esa visión ya estaba en peligro: hasta en la ficción temprana de Holmberg, la actividad reguladora de las nuevas instituciones del país muchas veces suprime la curiosidad y la investigación científica. Cuando llegamos a Olimpio Pitango de Monalia, treinta años después, los científicos se desviven para servir un programa político de modernización rápida y una manipulación nacionalista de las masas.

En muchos sentidos, la ambivalencia de Holmberg hacia el rol transformador de la ciencia en la sociedad lo convierte en un ejemplo típico de su generación. Como observa Oscar Terán, lo que destaca del proceso modernizador en Argentina es que sus promotores más entusiastas eran también los que expresaban mayores dudas sobre las 
consecuencias de sus reformas. Sostiene que "[...] en el seno de este sector que apuesta a la modernización y al progreso se desplieguen una serie de discursos complejos y correctivos que desearían cumplir el papel de la lanza mítica capaz de curar las heridas que ella misma produce" (Terán 20).

Fue ese espíritu, sugiere Terán, el que llevó a Vicente Quesada a lamentar la desaparición de viejas granjas y cipreses altos para hacer lugar a los ferrocarriles, pero al mismo tiempo a desear una sociedad futura enriquecida por costumbres y bienes europeos (Terán 20). A diferencia de Quesada o Miguel Cané, sin embargo, Holmberg no pone en duda los beneficios del progreso científico, sino la capacidad de las nuevas instituciones reguladoras de la nación para asimilar las ideas innovadoras y poco ortodoxas que alimentan el avance científico. La cuestión clave que surge de su ficción es cómo hacer circular esas ideas. La fantasía, como hemos visto, viene a ser para él la mejor y la peor de las herramientas en esta misión: sumamente poderosa como estímulo a la imaginación y capaz de inspirar una pasión y una fascinación por lo que queda por conocer pero -simultáneamente- cómplice en la subyugación de las masas a la demagogia política y la protección de los intereses de la élite. Holmberg lleva a cabo una autocrítica de su propio empleo de la ficción en las páginas de sus fantasías científicas.

En lugar de la educación de las masas, es quizá la cuestión de su gobierno la que surge como más perturbadora en las novelas de Holmberg. Su exploración reflexiva de la literatura fantástica revela el lado oscuro del impulso utópico de su generación hacia la modernización y el progreso, al sugerir que, a veces, estos proyectos tenían menos que ver con el igualitarismo y más con la conservación del status quo de la élite frente a las masas en aumento y la creciente amenaza que suponían para la estructura tradicional de la sociedad argentina.

\section{BiBLIOGRAFÍA}

Bruno, Paula. Pioneros culturales de la Argentina: Biografias de una época, 18601910. Buenos Aires: Siglo XXI, 2011.

Cazaux, Diana. Historia de la divulgación cientifica en la Argentina. Buenos Aires: Teseo, 2010.

Cortiñas, Sergio. "Un recorrido por la historia del libro de divulgación científica". Quark 37-38 (2006): 54-64.

Crash Solomonoff, Pablo. "Eduardo Holmberg: eslabón perdido en Marte". Viaje maravilloso del señor Nic-Nac al planeta Marte. Buenos Aires: Biblioteca Nacional/Colihue, 2006. 11-25.

Evans, Arthur B. "Nineteenth-Century SF." The Routledge Companion to Science Fiction. Mark Bould y otros, eds. Londres: Routledge, 2009. 13-22.

Flammarion, Camille. La pluralidad de los mundos habitados. Madrid: Gaspar y Roig, 1877. 
Los mundos imaginarios y los mundos reales. Viaje pintoresco al cielo. Madrid: Gaspar y Roig, 1873.

Lumen. Madrid: Gaspar y Roig, 1874.

Frederick, Bonnie. "A State of Conviction, A State of Feeling: Scientific and Literary Discourses in the Works of Three Argentine Writers, 1879-1908." Latin American Literary Review 19/38 (1991): 48-61.

Gasparini, Sandra. Espectros de la ciencia: Fantasías cientificas de la Argentina del siglo XIX. Buenos Aires: Santiago Arcos, 2012.

"La fantasía científica: Un género moderno". El brote de los géneros. Alejandra Laera, ed. Buenos Aires: Emecé, 2010. 119-47.

Haywood Ferreira, Rachel. The Emergence of Latin American Science Fiction. Middletown: Wesleyan UP, 2011.

Holmberg, Eduardo Ladislao. Dos partidos en lucha: Fantasía científica. Buenos Aires: Corregidor, 2005.

"El Museo de Buenos Aires: Su pasado-su presente-su porvenir". El naturalista argentino Tomo 1, Entrega 2; 1878. 33-43.

Olimpio Pitango de Monalia. Buenos Aires: Ediciones Solar, 1994.

Viaje maravilloso del señor Nic-Nac al planeta Marte. Buenos Aires: Biblioteca Nacional/Colihue, 2006.

Laera, Alejandra. Introducción. El brote de los géneros. Alejandra Laera, ed. Buenos Aires: Emecé, 2010. 7-12.

"Novelas argentinas (circulación, debates y escritores en el último cuarto del siglo XIX)". El brote de los géneros. Alejandra Laera, ed. Buenos Aires: Emecé, 2010. 95-118.

Le Bon, Gustave. Psicología de las masas. Alfredo Guera Miralles, trad. Madrid: Ediciones Morata, 1995.

Pagés Larraya, Antonio. "Estudio preliminar". Cuentos fantásticos. Buenos Aires: Hachette, 1957. 7-98.

Pérez Rasetti, Carlos. "La locura lúcida: Ficción, ciencia y locura en las fantasías científicas de Holmberg". Literatura argentina: Perspectivas de fin de siglo. María Celia Vázquez y Sergio Pastormerlo, eds. Buenos Aires: Eudeba, 2001. 207-26.

Rodríguez, Julia. Civilizing Argentina: Science, Medicine, and the Modern State. Chapel Hill: U of North Carolina P, 2006.

Rodríguez Pérsico, Adriana. "'Las reliquias del banquete’ darwinista: E. Holmberg, escritor e cientifico". MLN 116/2 (2001): 371-91.

Relatos de época: una cartografía de América Latina, 1880-1920. Rosario: Beatriz Viterbo, 2008.

Terán, Oscar. Vida intelectual en el Buenos Aires de fin-de-siglo (1880-1910): Derivas de la cultura cientifica. Buenos Aires: Fondo de Cultura Económica, 2000. 
